\title{
Spatial Interactions between the Settlement Network, Natural Landscape and Zones of Economic Activities: A Case Study in a Greek Region
}

\author{
Athena Yiannakou ${ }^{1, *}$ (D), Dimosthenis Eppas ${ }^{2}$ and Dimitra Zeka ${ }^{2}$ \\ 1 School of Spatial Planning and Development, Aristotle University of Thessaloniki, \\ 54124 Thessaloniki, Greece \\ 2 Geochoros Meletitiki SA, Urban and Regional Planner, 54642 Thessaloniki, Greece; \\ e-demo@geochoros.gr (D.E.); dimitra@geochoros.gr (D.Z.) \\ * Correspondence: adgianna@plandevel.auth.gr; Tel.: +30-231-099-5726
}

Received: 3 August 2017; Accepted: 22 September 2017; Published: 25 September 2017

\begin{abstract}
The structure of a settlement network has been influenced historically by physical, geographical and socioeconomic factors. Theories of spatial development have focused on the interaction between urban areas and socioeconomic processes considering the natural surroundings as a steady parameter rather than a potentially varying element contributing to spatial development. Over the past 25 years in Greece, a number of socio-economic factors along with improvements in transport infrastructure led to crucial changes in the traditional settlement system. The development of new economic activities was often associated with the special characteristics of the natural landscape. In this way, natural landscape as a dynamic element interacts with the built environment and the economic activities of a place, leading to the formation of new clusters of relationships. Using the case study of the Region of Western Macedonia, a mountainous, border zone Greek region, and based on an interactive framework of analysis whereby human and natural systems are considered strongly interconnected, this paper examines the spatial interactions between the settlement network, as the basic representation of human activity, the natural landscape, as a crucial element of the natural system, and the dynamic zones of economic activities, as a parameter that encompasses crucial attributes of both human and natural systems. The paper proposes that the heterogeneity of these interactions and the way they affect the thresholds and resilience of a specific place are important for the understanding of spatial change and for an integrated spatial planning for sustainable development.
\end{abstract}

Keywords: settlement network; economic activities; natural landscape; spatial interactions; Region of Western Macedonia

\section{Introduction: The Coupling of Human and Natural Systems and Spatial Planning}

The interaction between human settlements and the natural environment has become a topic of interest in spatial planning over the last few decades, mainly through the study of sustainable development [1-3]. This approach has given priority to the environmental agenda, meaning that the environmental axiom of sustainable development was considered to be more important than socioeconomic concerns. Yet, the development and the pattern of the settlement network, considered here as the set of human settlements within a specific spatial unit, has been influenced historically by physical, geographical and socioeconomic factors. This issue has been the main concern of historical geography, which has studied the effect of various physico-geographical and socioeconomic factors on the development of settlements, thus illustrating the configuration of specific places' historical features, given that historically, most interactions between humans and the natural world have taken 
place locally [4]. The study of human ecology emphasizes the complex 'coevolution', which has been claimed to shape the interactions between ecosystem components and human societies [5]. On the other hand, theories of spatial development and urban geography have focused on the interaction between urban settlements and socioeconomic processes [6], sometimes ignoring the natural environment and usually establishing it as a background of spatial reference; thereby viewing it as a steady parameter, rather than a potentially changing element contributing to spatial development [7] or to cultural and natural processes that adapt to each other and affect the territories [8]. The importance of the relationship between human settlements and the natural environment has emerged from various studies that have focused on the landscape. These studies highlight the natural environment and landscape surrounding settlements, identifying it as a dynamic, evolving and multifunctional element, which interacts with both the built environment and the economic activity of a place and forms new clusters of relationships [8-10].

Over the last decade, and as a part of the broader research on the vulnerability and resilience of different places, several studies have sought a more interdisciplinary approach and modeling of what they have called 'coupled socio-ecological' or 'human and natural systems' $[4,11,12]$. Through these approaches, an explicit consideration of the interaction between the social and the ecological systems is sought [11] and often within the resilience approach emphasizing non-linear dynamics, thresholds, uncertainties and interplays between periods of gradual change with periods of rapid change [13]. Liu et al. [4] have pointed out that people constantly interact with natural systems, resulting in the formation and development of what is called "coupled human and natural systems" (CHANS), which are characterized by complex organizational, spatial and temporal connections. These connections, or couplings, have evolved through direct and indirect interactions extending from the local to the global scale and from simple to complex structures and processes. An understanding of these couplings and of the characteristics arising from them could lead to the development of more effective policies for ecological and socioeconomic sustainability.

Studying specific areas in different parts of the world, Liu et al. [12] found that coupled systems have various degrees of resistance, meaning various degrees of ability to maintain similar structures and functions in the wake of major disturbances in ongoing development. What is interesting is that CHANS display many emerging and unique properties, which belong neither to natural, nor man-made systems, but rather, which arise from interactions between them. Couplings within and among CHANS take place at multiple spatial levels, ranging from local to global, and change over time. Of course, the interactions between human and natural systems on a regional and global scale are becoming of increasing interest because human activities are connected worldwide. Generally, the pervasive human influence has dramatically altered the evolutionary paths of many species. As Liu et al. [4] stated, "even areas explicitly buffered from human impacts, such as protected areas (e.g., nature reserves), are the outcome of human decisions and are influenced by global responses to human disturbances, such as climate change" (p. 640).

In Greece, in the domain of spatial planning, the study of settlements has focused primarily on an understanding either of the role of their hierarchical relationships in determining spatial planning areas, or of the concentration and deconcentration characteristics of the urban settlement system, or of their contribution to the formation of the patterns of regional development in the country [14-18]. Spatial planning by its normative objectives seeks to reflect a balance of decisions affecting the built environment, on the one hand, and the natural environment, on the other. Yet, the way in which the coupling of human and natural systems, as a single analytical field, affects the spatial characteristics and the vulnerability or resilience of an area over time needs further research. The emergence, for instance, of the natural landscape as a key element in the agenda of spatial planning, which was also adopted in the Greek planning system in the last decade $[19,20]$, has given rise to the need for a comprehensive approach that may provide a more plausible understanding of the way human and natural systems co-function. 
Over the last 25 years, a combination of factors has led to critical changes in, and/or alternations of, the traditional system of settlements and their relationship with the natural environment. These factors are, firstly, urban sprawl and its impacts on the natural environment resulting from the search for new sites for primary and secondary residence, secondly, the construction of a number of major motorways, which have transformed the natural and historical seclusion of large areas, and thirdly, the expansion of activities such as tourism and recreation to new places other than the conventional ones, i.e., other than the mass-tourism coastal areas. These alterations have occurred due to the new economic activities that emerged in the former isolated areas, activities that are often associated with both the broader spatial processes and with the characteristics of the natural environment.

A study of the interaction between human and natural systems, in the Greek, mountainous, border zone Region of Western Macedonia, can enrich our knowledge of the complex nature of this interaction, providing further insight into reciprocal effects. This enhanced insight is considered essential for the better integration of the natural and human environment into spatial planning. The paper adopts an approach that features an interactive framework of analysis and views the natural environment as a dynamic, rather than a static, element. From the three categories of interactions (couplings) examined by Liu et al. [4]—organizational, spatial and temporal—the present paper attempts to explore spatial interactions and their heterogeneity, with reference to levels ranging from the local to the regional. The temporal dimension, which traces changes over time, is also examined over a recent period spanning almost 25 years. This period, while relatively short, was however crucial for the Region's vulnerability and resilience. Based on extensive fieldwork research conducted by the authors, during the preparation of the "Study for the Evaluation, Amendment and Specifications of the Regional Spatial Plan of Western Macedonia" and the accompanying "Landscape Study" [21,22], this paper examines the spatial interactions within the Region of Western Macedonia between the settlement network, as the basic representation of human activity, the natural landscape, as a crucial element of the natural system, and the dynamic zones of economic activities, as a parameter that encompass crucial attributes of both human and natural systems. The second section presents the basic data, which portray some major attributes of the Region, such as location, administrative organization, natural ecosystems, settlement system and population dynamics. The third section focuses on an analysis of the spatial interactions between the natural landscape (expressed by land morphology and land cover), the settlement network (expressed by its spatial pattern and cultural heritage) and the dynamic zones of economic activity. The final section provides a discussion of how the heterogeneity of these interactions and their temporal changes affect the thresholds and resilience of a specific place and thus broadens the context of spatial planning.

\section{The Human and Natural System and the Settlement Structure of the Region of Western Macedonia: Basic Data}

\subsection{Portraying the Overall Human and Natural System of the Region}

The Region of Western Macedonia is located in the northwest part of the country traditionally considered as a "peripheral" location. Despite its peripheral location in the country, it has a key position in the Western Balkans as it is a natural gateway to Greece's northwest neighboring countries (Former Yugoslav Republic of Macedonia, Albania). Administratively speaking, it is divided in four Regional Units (RU), the RUs of Kozani, Florina, Kastoria and Grevena (Figure 1). It is predominantly a mountainous area with $83 \%$ of its territory being covered by mountainous and semi-mountainous land and the only Region of the country with no outlet to the sea. Geomorphologically, it is mainly characterized by large mountains, which traverse the Region (Pindos, Voras, Vermio, Pieria, Kamvounia, Chasia), and by a variety of water sources. The largest river in Greece, Aliakmonas, stems from this Region and travels down through it, passing through three of its RUs Kastoria, Kozani and Grevena. The Region also has many natural and artificial lakes, with the most important natural ones being Great and Small Prespa, the lakes of Kastoria, Vegoritida, Cheimaditida, Zazari and Petron and two of the most important artificial lakes in the country, Polyfytos and Hilarion. 


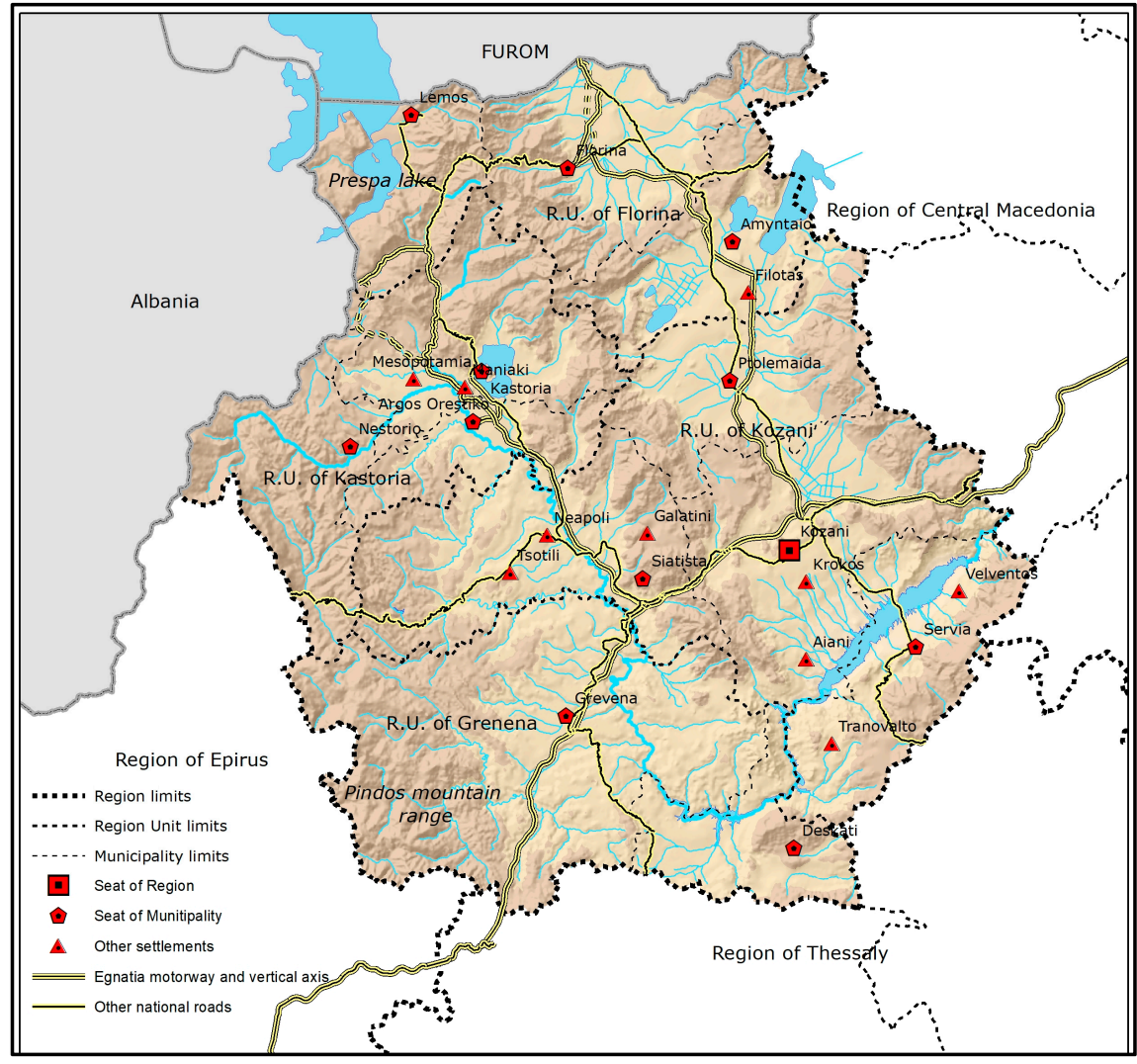

Figure 1. The Region of Western Macedonia: Regional units and main cities and towns.

It is, generally, a sparsely-populated region, given that the permanent population is 283,689 inhabitants [23]. Its gross density is 30 inhabitants (inhab.) $/ \mathrm{km}^{2}$, which is considerably lower than the average gross density of the country $\left(81.75\right.$ inhab. $\left./ \mathrm{km}^{2}\right)$. In terms of population size, compared to other regions, it is the third smallest in the country (after the Regions of Northern Aegean and Ionian Islands) and, therefore, the least populated region of the mainland. Approximately $50 \%$ of its population is concentrated in the RU of Kozani, where the main city and capital of the Region is located. In the decade 2001-2011, the total population showed a remarkable reduction, a reduction greater than that of the country's total population during the same period, which also decreased because of the recession after the financial crisis.

The Region of Western Macedonia is characterized by its abundant natural resources, (mineral resources, water resources, forests), which provide nationwide benefits. It has the largest lignite reserves in the country, the use of which contributes decisively to national electricity production, significant reserves of ores, industrial minerals and marble, and there are also several, scattered gravel pits. Almost $65 \%$ of the surface water of the country is located in the Region, the use of which contributes to the energy supply of the country and supports productive and urban activities at an inter-regional level. The region's forests are home to some important species of wild life, as well as giving protection to habitats in the wider environment while, at the same time, providing an important source of productive capital.

In terms of regional economy, a contradiction arises, as the Region shows a growing GDP per capita, but a high unemployment rate over time. Therefore, it is fair to say that it is a predominantly industrial Region, which, however, fails to use its distinctive assets to the advantage of the regional labor market. Western Macedonia is specialized in the sectors of energy, mining and fur industry, which makes it an eminently industrial region and one of the EU regions with a highly specialized regional economy. The energy industry is mainly related to the activity of the Public Power Corporation and 
the operation of five Thermal Power Plants (TPP), rendering the Region the most important center of power production in the country. Thus, it hosts a predominantly export-oriented economy, closely tied to national-level decisions. Indeed, although the proportion of energy produced from lignite is gradually decreasing over time, the Region still produces half of the country's electricity. The Region's mineral industry is an economic sector of national importance due to the fact that ores and other industrial minerals mined in its territory provide raw materials that make up a significant proportion of the country's exports. Quarrying has also a clear export orientation, constituting a source of income for the local socioeconomic systems.

The export-oriented profile of the Region is enhanced by the traditional fur industry, which has also provided a specialization in specific areas of the Region. This sector has direct links with, and dependencies on, global demand [24], which can enhance either the resilience of the Region in relation to the national economy or its vulnerability due to fluctuations of the global market. This situation explains the initial great development of fur breeding, due to the increased skin prices, that was observed during the first years of the economic crisis after 2008-2009. However, in the last 3-4 years, there has been a great decline of the industry in international markets.

From the second half of the 1990s onwards, the Region began to emerge as one of the most attractive areas for winter and alternative tourism, resulting in the development of tourism activity in some zones and, thus, in the achievement of a slight degree of economic diversification. The goal of intensive tourism development has been expedited by the Region's highly valued natural environment, in combination with its rich cultural heritage and the drastic improvement in accessibility, following the completion of the Egnatia Motorway [25]. Moreover, in recent years, significant indications of development within specific branches of the primary and secondary sectors have been recorded.

The Region's natural systems' zones are characterized by connectivity; they have great ecological and aesthetic value and contain diverse protected ecosystems, which, being included in both the European protected networks and the broader ecosystem zones institutionally defined as National Forests (Pindos National Forest) and National Parks (Prespa Lake National Park), are of international importance. There is also a large number of listed settlements or of architectural significance, many of which belong to ensembles of small settlements with common cultural heritage characteristics. A number of archaeological sites and monuments, the majority of which are concentrated in the RUs of Kozani and Kastoria, are also a significant cultural heritage stock. Forestry is the dominant land cover of the Region. In contrast, cultivated land covers only one third of the Region's area. Mineral extraction takes place in large zones of the eastern part of the Region, as well as in other smaller scattered zones.

\subsection{Structure of the Settlement Network and Population Dynamics}

Based on the 2011 census, the settlement network of the Region of Western Macedonia consists of as many as 557 settlements, having an average size of 509 inhabitants per settlement. Table 1 and Figure 2 illustrate the settlements by population size classes.

Table 1. Residential network by population size class, 2011 [23].

\begin{tabular}{ccccc}
\hline \multirow{2}{*}{ Population Size Class } & $\begin{array}{c}\text { Number of } \\
\text { Settlements }\end{array}$ & \multicolumn{2}{c}{ Population $\mathbf{2 0 1 1}$} & \multirow{2}{*}{$\begin{array}{c}\text { Persons per } \\
\text { Settlement }\end{array}$} \\
\cline { 3 - 4 } & & People & $\mathbf{\%}$ & \\
Zero population & 21 & 0 & 0 & 0 \\
Up to 100 people & 239 & 9721 & 3.43 & 41 \\
101-500 people & 207 & 50,846 & 17.92 & 246 \\
501-2000 people & 73 & 63,736 & 22.47 & 873 \\
2001-5000 people & 10 & 29,020 & 10.23 & 2902 \\
5001-10,000 people & 2 & 12,963 & 4.57 & 6482 \\
Over 10,000 people (urban centers) & 5 & 117,403 & 41.38 & 23,481 \\
Inhabited settlements & $\mathbf{5 5 7}$ & $\mathbf{2 8 3 , 6 8 9}$ & $\mathbf{1 0 0}$ & $\mathbf{5 0 9}$ \\
\hline
\end{tabular}




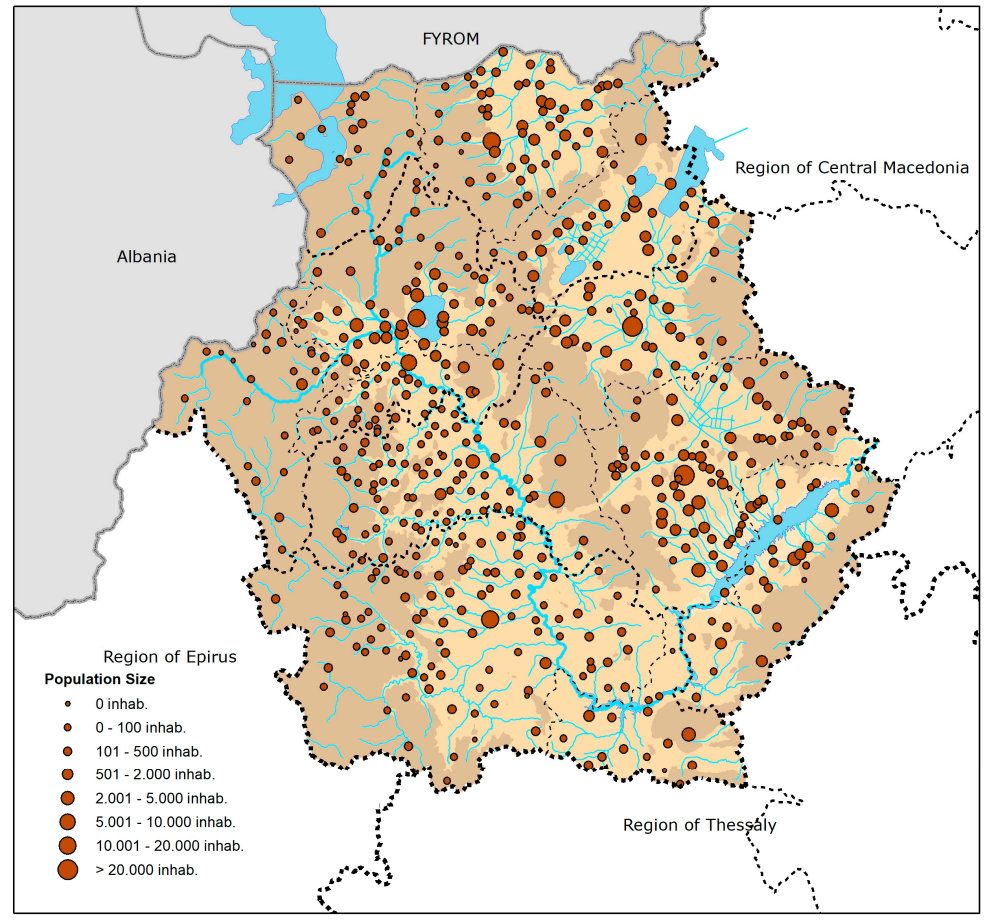

Figure 2. Classification of settlement network, 2011 (inhab.: inhabitants).

As can be seen from Table 1, apart from the 21 uninhabited settlements, the population of the vast majority of the remaining ones (519 settlements) is less than 2000 people, which represents $43.82 \%$ of the Region's population. Only 10 settlements belong to the intermediate class of 2001-5000 inhabitants (inhab.), with an average population size of up to 3000 people. Moreover, the population of only two settlements is within the rage of 5001-10,000 inhab., namely Siatista in RU Kozani and Argos Orestiko in RU Kastoria. There are five urban centers (more than 10,000 inhab.), which are characterized by a small population size while accounting for $41.38 \%$ of the Region's population. More specifically, these are the capitals of the four RUs (Kozani, Kastoria, Florina and Grevena) along with Ptolemaida in the $\mathrm{RU}$ of Kozani. Therefore, although the Region is characterized by a very dense settlement network, in terms of population, it consists of a few small urban and semi-urban centers and of numerous very small settlements with populations of less than 2000 inhabitants.

Figures 3 and 4 illustrate the population change over the decades between 1991 and 2001 and between 2001 and 2011. Between 1991 and 2001, the urban centers of the Region (categories of 10,001-20,000 inhab. and of over 20,000 inhab.) experienced an increase in population, except for Kastoria (category of 10,001-20,000 inhab.), which showed a decline. Regarding the two settlements of class 5001-10,000 inhab., both of which are in the fur industry zone along with Kastoria, only Argos Orestiko's population increased, while Siatista's decreased. Most of the settlements in the category of 2001-5000 inhab. exhibited population growth, while in most of the settlements belonging to the smaller categories (less than 2000 inhab.), a fall in population was observed. It is worth pointing out that the majority of small mountainous settlements in the Municipality of Grevena, as well as the majority of settlements in the Prespa lake area (RU of Florina) recorded an increase in their population. These settlements constituted zones that performed a dynamic development in the tourism sector. In contrast, a decline in population was observed in settlements of the mountainous zones of Voio and Askio, which strengthened their historical depopulation. It is noteworthy that in the Municipality of Kozani, the settlements that showed an increase in inhabitants were mainly located around the city of Kozani, functioning mostly as suburban settlements. A similar pattern, although not to such a great extent, can be observed in the Municipality of Florina, as there as well, settlements with increasing population rates were in close proximity to the city of Florina. 


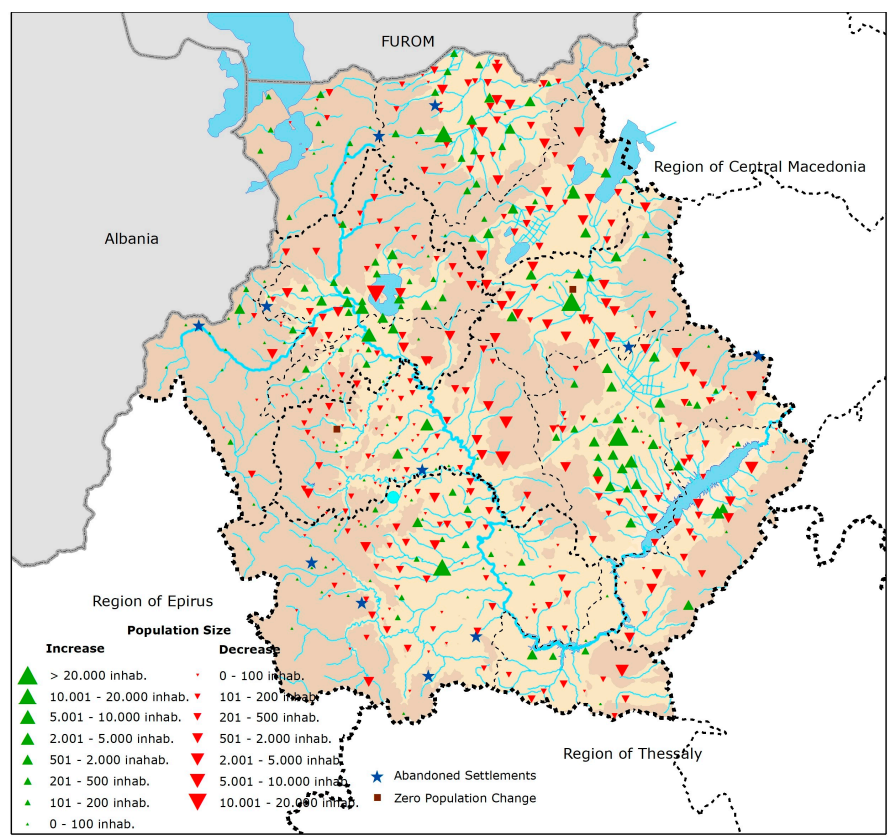

Figure 3. Population change 1991-2001.

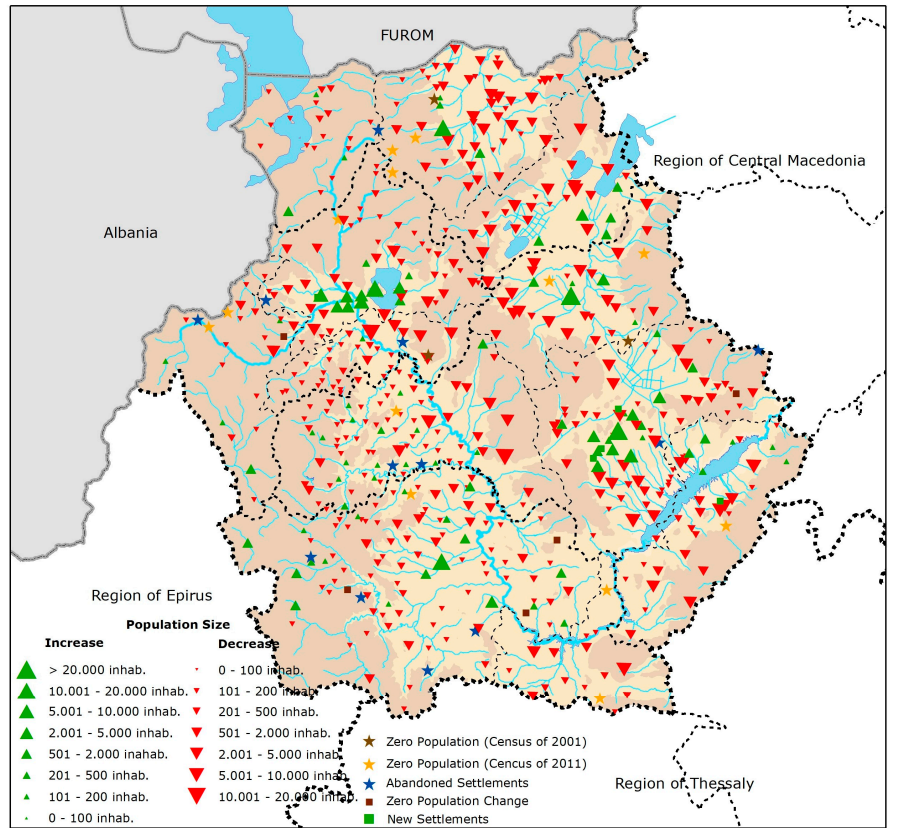

Figure 4. Population change 2001-2011.

A general finding that emerges is that settlements-mainly the most remote and mountainous ones-that suffered the greatest decline in population in past decades are the same ones that showed an increase in their population from the decade 1991-2001. This population growth can be attributed to two factors: The first factor was the change in the economic activity of the Region, mainly due to the development of a regional tourist-orientated economy (indicated below), which was followed by improved access to the settlements. The second factor was climate change, as the reduction in snowfall and the slight rise of temperature in mountainous settlements resulted in better living conditions there, especially during the winter. Moreover, it can be observed that, during this decade, cities attracted new inhabitants, both to their center and to the surrounding settlements. 
During the decade 2001-2011, all urban centers of the Region (categories of 10,001-20,000 inhab. and over 20,000 inhab.) experienced population growth. Regarding the two settlements in the class of 5001-10,000 inhab., both showed a population decrease, while on the contrary, four out of ten settlements in the class of 2001-5000 inhab. showed a population increase. As for the settlements of smaller categories (under 2000 inhab.), a general decline in population was observed, as in the previous decade. However, some of the mountainous settlements of the Municipality of Grevena continued to be an exception, as they increased their population. Population growth was also apparent in some small settlements in the Municipality of Orestidos. Notably, in the Municipalities of Kozani and Kastoria, the settlements that showed an increase were, mainly, in close proximity to the cities of Kozani and Kastoria.

Broadly speaking, the pattern of population growth from 2001- 2011 was similar to the previous decade, albeit less dynamic, as it was affected by the overall depopulation trends. In other words, some mountainous and remote settlements, as well as the cities and their perimeter settlements continued to show an increase in their population, despite the overall depopulation trend, which in the Region was higher than the one recorded in the country as a whole.

\section{Analysis of the Spatial Interactions between the Settlement Network, Natural Landscape and Dynamic Zones of Economic Activities}

\subsection{Methodology}

After the overall portraying of the main attributes of the Region's human and natural environment and the analysis of the settlement structure and population dynamics in the period 1991-2011, the study focuses on tracing basic spatial interactions at an intraregional level. For this reason, two fields of interaction were investigated: (a) between the settlement structure and natural landscape and (b) between the settlement structure and the dynamic zones of economic activities, as they have formed over time. The study of these interactions is based on a Geographic Information System (GIS) overlay analysis. Essentially, by mapping and then overlaying the pattern of the landscape features and settlement structure, we were able to identify correlations between different layers. The basic source for information of critical characteristics of the natural environment was the 2012 CORINE land cover dataset of the CORINE (Coordination of Information on the Environment) program of the European Commission.

The study of the correlation between settlement network and natural landscape follows a methodology for typologizing landscape features proposed by the Final Project Report of the European Landscape Character Areas [26] as modified by the "Landscape Study" of the Region of Western Macedonia [22]. According to this typology, two critical dimensions define the landscape, the bio-physical (form and function of the landscape: geology, topography, land morphology, climate, soil, vegetation, land cover, wild life and biodiversity) and the human (human influence upon the form of landscape: land use, historical-temporal dimensions, spatial pattern of settlements, cultural heritage). In the present study, the basic parameters taken into consideration are land morphology and land cover from a bio-physical perspective, along with the spatial pattern of the settlement network and cultural heritage from a human perspective.

The dynamic zones of economic activities were further defined based on extensive and analytical field recording of the land uses, the intensity of occupancy along with the specific built-up installations located in them, while some complementary evidence from economic indicators, such GDP structure per RU, was also taken into consideration.

\subsection{Spatial Interactions between the Settlement Network and Natural Landscape}

The Region of Western Macedonia is a predominantly mountainous region. The plain zone occupies about $17 \%$ of its total area, the semi-mountainous area approximately $31 \%$ and the mountainous area $52 \%$. The RU of Grevena is the most mountainous one, as its lowland zone accounts 
only for $7 \%$ of the total land. Conversely, the RU of Florina and Kozani have the greatest proportion of lowland areas, $26 \%$ and $23 \%$ respectively. In relation to elevation zones, $2.92 \%$ of the Region's area lies at an elevation of below $400 \mathrm{~m}, 44.73 \%$ between 400 and $800 \mathrm{~m}$ and the remaining $52.35 \%$ at an elevation of over $800 \mathrm{~m}$. It is noteworthy that all areas in Western Macedonia lie at elevations of over $200 \mathrm{~m}$.

The density of settlements, in almost the entire territory of the Region, is remarkable. In order to study how dense the Region's settlement system is, a buffer zone allowing a 3-km radius from any settlement was chosen. Three kilometers was considered to approximate the average daily distance that could be covered easily on foot, regardless of the size of the settlement, the elevation or the incline. It is evident that the Region's settlement network is very dense covering most of its territory. In fact, in the largest part of the Region, these 3-km buffer zones overlap, as shown in Figure 5, illustrating the correlations between the various settlements, the terrain (elevation zones) and the land coverage (based on CORINE Land Cover). There are only four settlements whose buffer zones do not overlap, all of which are located at elevations of more than $800 \mathrm{~m}$.

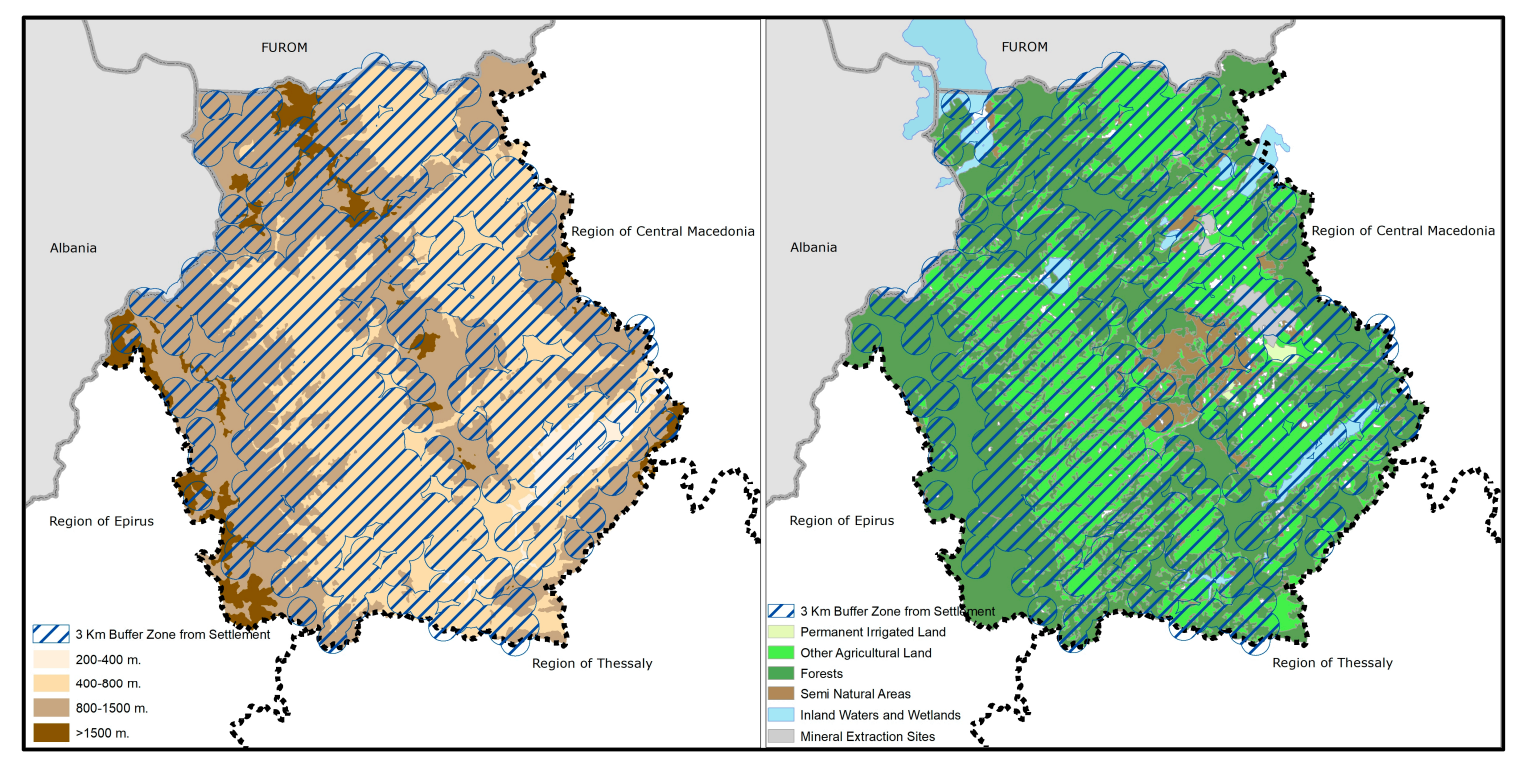

Figure 5. Correlation of settlement network with the elevation and the land cover, 2012.

Comparing the distribution of settlements in relation to elevation, it is apparent that the Region's settlement network covers all the mountainous (800-1500 m), semi-mountainous (400-800 m) and lowland (200-400 m) areas, with significant density. The only exceptions are small, very mountainous areas, with elevation of over $1500 \mathrm{~m}$. As shown in Figure 5, a zone in the mountainous complex Askio-Vourino, a zone in the mountainous complex Grammos-Smolikas and the western foothills of mountain Vora are zones lying at elevations of between 800 and $1500 \mathrm{~m}$, which are not covered by settlement networks. There are five mountainous settlements, Grammos, Pentalofos, Eptachori, Samarina and Vigla, lying at an elevation of between 800 and $1500 \mathrm{~m}$, located at a relatively long distance away from the dense complexes of settlements. It should be noted that Grammos is currently uninhabitable, while Vigla is not a settlement, but a ski resort.

Based on the altitudinal zones, 20 settlements are recorded in the zone $0-400 \mathrm{~m}$, a zone that actually ranges from 200 to $400 \mathrm{~m}$. All these settlements are located around the artificial Lake Polyfytos, and represent only $3.59 \%$ of the Region's settlements. The majority of settlements, 346 in number, lie at an elevation of between 400 and $800 \mathrm{~m}$ and account for $62.12 \%$ of the Region's settlements. One third, $34.29 \%$, of the Region's settlements, $191 \mathrm{in}$ total, lie at an elevation of $800 \mathrm{~m}$ or higher. This significant number of settlements proves the historical dependence of settlements on the economic activity in the mountainous zone of the Region. 
Regarding the relationship between settlements and land cover, the Region's settlement network is developed in forested, as well as agricultural areas. As can be observed from Figure 6, some woodland areas in the axis of Grammos-Smolikas-North Pindos, fallow or sparsely-vegetated lands in Mount Askio and highly productive agricultural land in the area between the cities of Kozani and Ptolemaida are areas of the Region that are not covered by settlement networks.

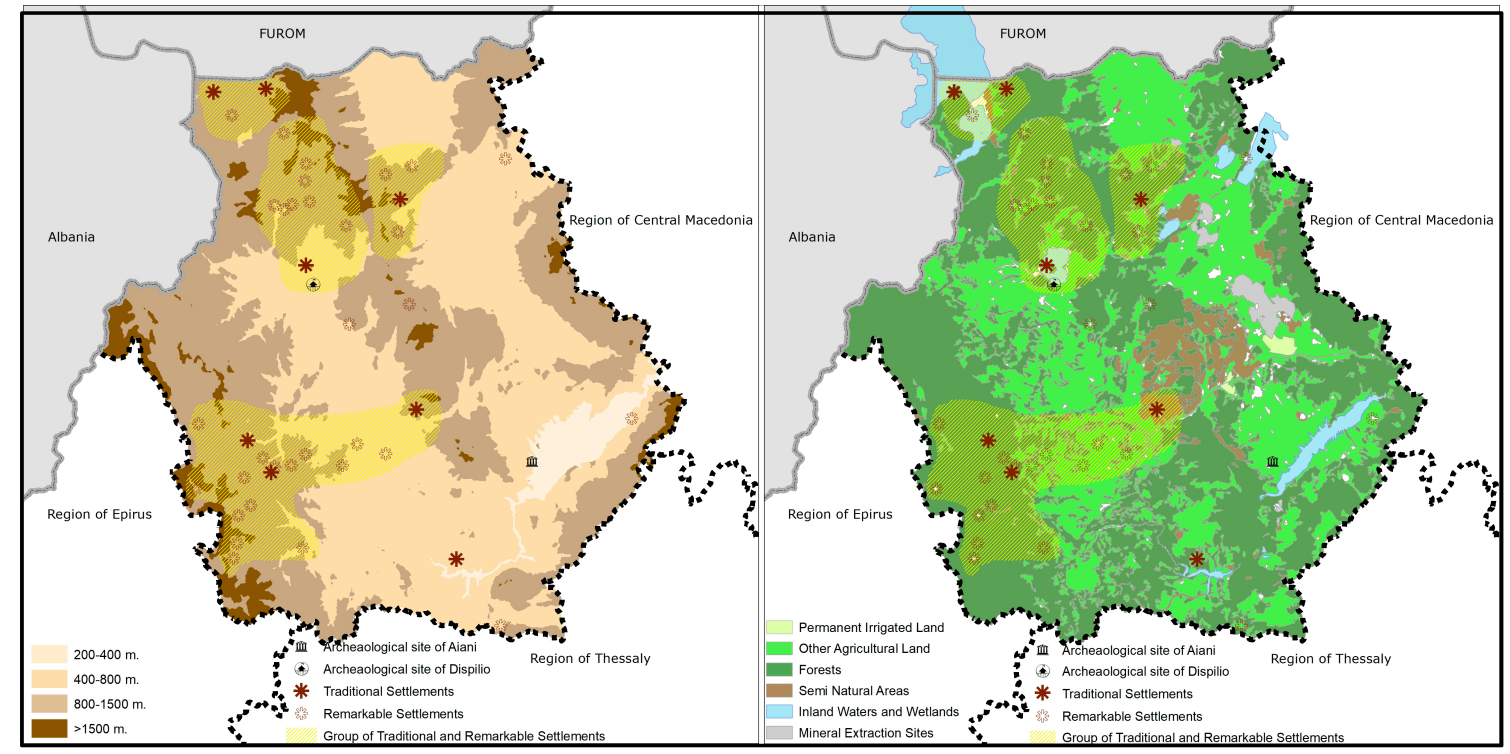

Figure 6. Correlation of traditional and remarkable settlements with the elevation and the land cover, 2012.

Across the Region, 40 settlements with significant architectural characteristics and historical heritage were recorded: eight of them are officially listed with the term "traditional" settlements, while the rest were recorded in the fieldwork as having remarkable architectural characteristics (indicated as "remarkable" settlements in Figure 6). In relation to elevation, the majority of these settlements are mountainous, as they are located in areas with an elevation of between 800 and $1500 \mathrm{~m}$, while seven of them are semi-mountainous, since their elevation ranges from 400 to $800 \mathrm{~m}$. As shown in Figure 6, the concentrations of architecturally-remarkable and traditional settlements can be observed mainly in mountainous areas, and less in the lowlands.

Finally, in relation to land cover, most of the architecturally-remarkable and traditional settlements within the Region, 23 in number, are located in forested areas, 12 in rural areas and 5 near lakes (Figure 6). The concentration of architecturally-remarkable and traditional settlements in mountainous and forested areas can be attributed primarily to the history and geography of the area, which resulted in the coupling of mountainous and residential areas within the territory of Western Macedonia as documented in the Region's history [27].

\subsection{Spatial Interactions between the Settlement Network and Dynamic Zones of Economic Activities}

Economic activities developed over time, within dynamic, individual zones. These zones, although they are overlapping in several parts of the Region, also contain large areas that are easily distinguished (Figure 7).

In the primary sector, the dynamic zones were determined primarily according to the produced agricultural product [28]. The agricultural branches have developed in areas characterized by lower elevations and gently sloping ground. The only exception is the area of the lake Prespa, where, in the slightly more undulating land, cultivation of beans takes place. The livestock areas occupy mainly higher elevation zones, apart from the fur farming, which takes place in the axis of Siatista-Kastoria, in 
the western part of the Region. The dynamic zones of the secondary sector are related to the sectors of energy, mining and fur industry. The lignite mining zones have been developed in the basin of Ptolemaida-Florina, in the eastern part of the Region, and in a few more scattered areas, mainly in the RU of Kozani and Florina. As for the rest of the ore and industrial minerals, mining and the quarrying activity, the dynamic zones are scattered throughout the Region. The energy sector has developed parallel to the lignite mining industry, as both of them are connected and can be traced to the axis Kozani-Ptolemaida-Amyntaio-Meliti, where large thermoelectric power plants operate. The fur industry has also developed in tandem with the fur farming industry, in the axis of Siatista-Kastoria. The most dynamic areas of the tertiary sector, within the Region, are related to tourism and are zones of environmentally-friendly, alternative tourism, with potential for further development. Areas of development related to the other sectors, such as trade and social infrastructure, have developed mainly in the Region's cities, especially in the capital city of Kozani. The development of these sectors is basically localized and, therefore, not as important a factor as others that affect the regional economy.

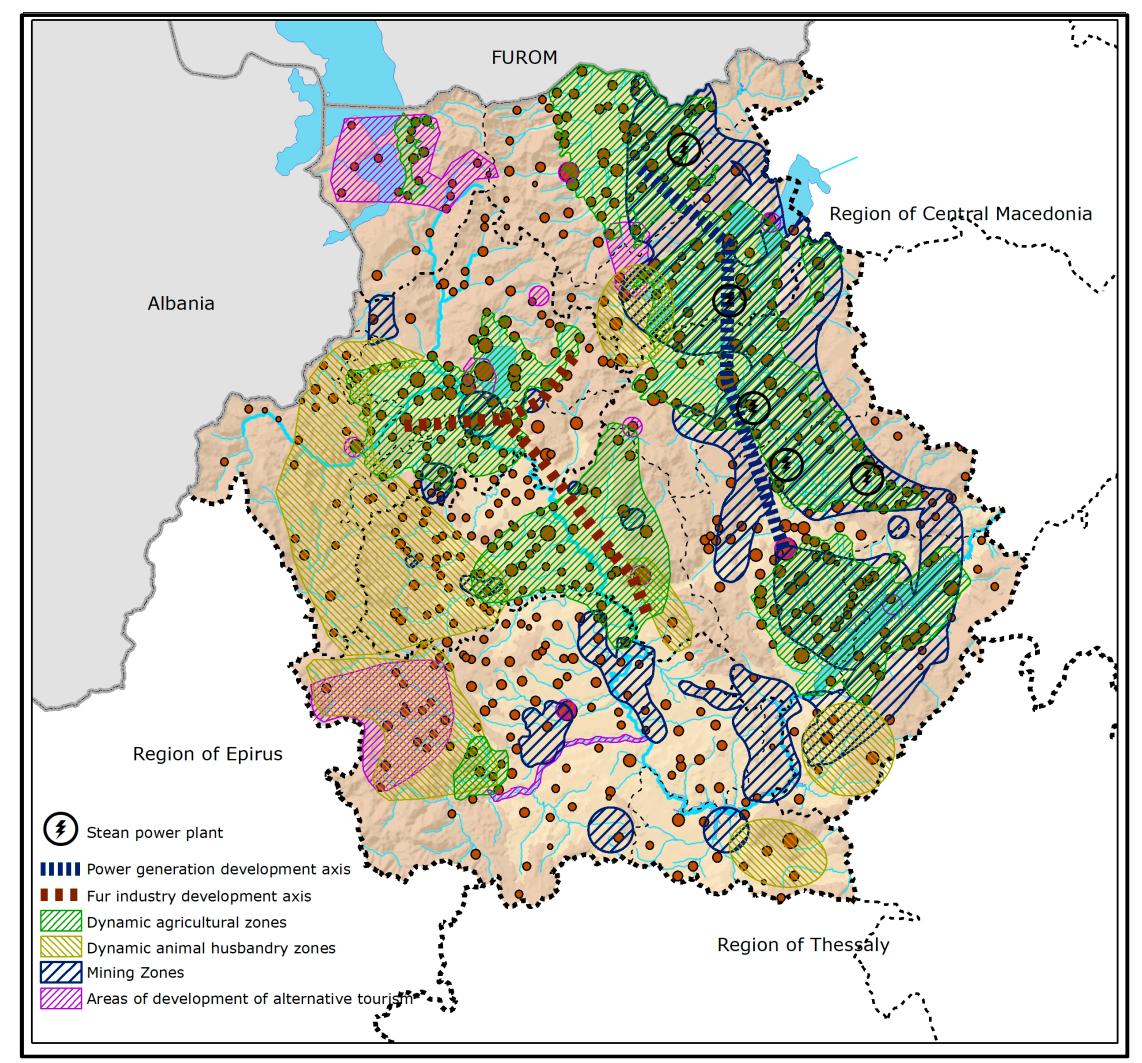

Figure 7. Correlation of the settlement network with dynamic zones of economic activities and elevation, 2012.

Looking at the spatial pattern that is formed between the settlement network and the dynamic zones of economic activities, the first crucial correlation (well documented in all relevant spatial planning studies) is the development of two major networks, alongside the two dynamic axes of productive activities of the secondary sector, namely the power generation development axis and the fur industry development axis. The first network consists of urban and semi-urban-more than 5000 inhabitants-settlements, including three out of five urban centers of the Region, namely Kozani, Ptolemaida and Florina, while the second network includes the other two urban centers, Kastoria and Grevena, and two semi-urban centers of over 5000 inhabitants. In the above networks, five out the total of 10 semi-urban settlements of 2000-5000 inhabitants, as well as several smaller settlements, are also included. 
A second important feature is that all semi-urban settlements of 2000-10,000 inhabitants, with the exception of two settlements that are in fact suburbs of an urban center, are also the nuclei of settlement networks developed in tandem with primary production. These networks are usually composed of one or two semi-urban settlements and several small or very small rural settlements. It should be noted here that all urban and semi-urban settlements, with the exception of Deskati in the RU of Grevena, are located within the elevation zone of $400-800 \mathrm{~m}$. Deskati, on the other hand, has an elevation of over $800 \mathrm{~m}$, on the historical root traversed by Vlach populations, and is the core settlement of a distinct network of small settlements, which has developed historically in tandem with livestock production.

Other smaller networks have developed mainly in concert with agricultural or livestock production, whereas during the last 20 years, the development of alternative forms of tourism has also played an important role in the development of these networks. Such are the cases of the settlements in the Prespa Lake area and in the mountainous range of Northern Pindos. These networks consist of very small settlements and either entirely or in large part lie at an elevation of over $800 \mathrm{~m}$. Furthermore, they very often consist of very small settlements, with no one settlement functioning as the core or center for the whole.

Looking at temporal dimension, in 1991-2001, at a period of population growth, both in the Region and in the separate RUs, population increase was recorded in the settlements within dynamic alternative tourism zones, even in the case of very small settlements, such as those in the areas of Prespa Lake and the mountainous range of Northern Pindos. In contrast, there has been a downward trend in the population within areas that have developed solely as livestock zones. No specific pattern can be identified in the zones of secondary sector development, nor in zones of agricultural development, as there are some areas that display positive changes and others negative ones. Positive changes can be observed within the settlements around the cities.

In 2001-2011, when the population change in the Region and in its RU was negative, a reduction in the population, within all the zones of economic activities, was observed. In this declining period, the only exception appears to have been the mountainous area Grevena-Northern Pindos, which falls within two zones, tourism and livestock. This area represents one of the major spatial changes of the 1991-2011 period, due to the increased number of visitors to its natural environment, the development of tourism and the drastic improvement in the Region's accessibility, from the two major urban centers of Northern Greece (Thessaloniki in the Region of Central Macedonia and Ioannina in the Region of Epirus) and in general from the rest of the country, due to the construction of the Egnatia motorway [25].

\section{Discussion and Conclusions}

The interactions and feedback between human and natural systems are very complex, and their current coupling is going through unprecedented and rapid changes, experiencing even closer ties on multiple levels [4]. The present study of the spatial interactions between the settlement network, natural landscape and dynamic zones of economic activity, on which this paper focused, could contribute to the understanding of the heterogeneity of the coupled human and natural systems at the regional scale and of the way spatial change and the specific characteristics it presents occur in each place. These intraregional interactions modify the external effects from other spatial scales (national or global) in many respects and form a particular region's thresholds, i.e., the transition points between alternate states, and resilience, i.e., its ability to retain similar structures and functioning after disturbances [4], at a specific period of time.

In the case study analyzed in this paper, the Region of Western Macedonia in Greece over the past 20-25 years, changes have been identified that have led to greater diversity in the common patterns of spatial trends. These changes have differentiated spatial patterns as regards location, size, classification and degree of urbanization of settlements, as well as the physical or functional isolation and the accessibility of various settlements. Thus, interesting differences regarding the natural environment and the dynamics created in relation to human intervention (habitation-population 
change and economic activities) provided the basis for the Region's resilience, as well as its thresholds. Therefore, for instance, in one part of the Region under investigation, the mining zone in the eastern part, the development of the energy sector may have contributed historically to the formation of an axis, where increased population concentration and dynamic population trends can be observed. This is, however, an area whose prospects are currently negatively affected both by the degradation of the natural environment and by external influences, on a national and supra-national spatial scale, which are caused by the necessary path to the post-lignite period and the ensuing energy policies. Similar trends have been recorded in the traditional fur industry development axis, which is strongly influenced by international fluctuations in the industry. However, historically, this development axis has demonstrated a long-term ability to maintain its long-term functioning despite disturbances, in other words to retain its long-term resilience. At the same time, positive developments have been recorded in small zones of the Region with networks of small, or very small, settlements; although they are part of the traditionally more isolated and mountainous area. These developments have been further enhanced by an important human initiative to improve accessibility resulting in the construction of the major road transport axis. This along with other factors has allowed the permanent re-habitation of areas that had been drastically depopulated in the past. In contrast, similar changes were not observed in other areas with significant tourism and agricultural activity (Prespa lakes area). All these trends suggest that developments of this kind are complex and diverse.

From the spatial planning point of view, this study contributes to a broadening of the framework of spatial analysis and settlement typology, so as to include, not only the classical elements, such as population hierarchies and rural/urban distinctions, but also the interactive attributes of settlement networks with the natural environment. Such a typology of course necessitates further analysis and comparative studies between various regions. At the policy level, the proposed approach requires the consideration, at an empirical level, of all major natural and human components and their actual interaction at a specific place and time, as suggested by Liu et al. [4].

In conclusion, the study of the coupling of human and natural systems should be explored in depth and mainly in comparison to the organizational, spatial and temporal dimensions of this coupling. Through these dimensions, the understanding of critical properties of a place, which belong to both its human and natural system, is enriched. More important are the challenges and opportunities for the formulation of spatial development strategies with integrated and comprehensive agendas, as well as interdisciplinary policies towards the creation of sustainable and productive spatial systems.

Author Contributions: Athena Yiannakou conceived of the concept of the article and wrote the article. Dimosthenis Eppas was responsible for the fieldwork and the mapping. Dimitra Zeka analyzed the settlement structures and their features. All authors contributed to the discussion.

Conflicts of Interest: The authors declare no conflict of interest.

\section{References}

1. Blowers, A. (Ed.) Planning for Sustainable Development, 1st ed.; Earthscan Publications Ltd.: London, UK, 1993; ISBN 1-85383-145-X.

2. Newman, P.; Jennings, I. Cities as Sustainable Ecosystems: Principles and Practices, 1st ed.; Island Press: Washington, DC, USA, 2008; ISBN 978-1-59726-188-3.

3. UN-Habitat. Planning Sustainable Cities: Global Report on Human Settlements 2009, 1st ed.; Earthscan Routledge: Oxon, UK, 2009; ISBN 978-18-4-407899-8.

4. Liu, J.G.; Dietz, T.; Carpenter, S.R.; Folke, C.; Alberti, M.; Redman, C.L.; Schneider, S.H.; Ostrom, E.; Pell, A.N.; Lubchenco, J.; et al. Coupled human and natural systems. Ambio 2007, 38, 639-649. [CrossRef]

5. Blondel, J. The 'Design' of Mediterranean Landscapes: A Millennial Story of Humans and Ecological Systems during the Historic Period. Hum. Ecol. 2006, 34, 713-729. [CrossRef]

6. Pacione, M. Urban Geography: A Global Perspective, 3rd ed.; Routledge: London, UK, 2013; ISBN 978-0-203-88192-7.

7. Goudie, A.S. The integration of human and physical geography. Trans. Inst. Br. Geogr. 1986, 11, 454-458. [CrossRef] 
8. Steiner, F. Landscape ecological urbanism: Origins and trajectories. Landsc. Urban Plan. 2011, 100, 333-337. [CrossRef]

9. Antrop, M. Landscape change and the urbanization process in Europe. Landsc. Urban Plan. 2004, 67, 9-26. [CrossRef]

10. Termorshuizen, J.W.; Opdam, P. Landscape services as a bridge between landscape ecology and sustainable development. Landsc. Ecol. 2009, 24, 1037-1052. [CrossRef]

11. Binder, C.R.; Hinkel, J.; Bots, P.W.G.; Pahl-Wostl, C. Comparison of frameworks for analyzing social-ecological systems. Ecol. Soc. 2013, 18, 26. [CrossRef]

12. Liu, J.G.; Dietz, T.; Carpenter, S.R.; Alberti, M.; Folke, C.; Moran, E.; Pell, A.N.; Deadman, P.; Kratz, T.; Lubchenco, J.; et al. Complexity of coupled human and natural systems. Science 2007, 317, 1513-1516. [CrossRef] [PubMed]

13. Folce, C. Resilience: The emergence of a perspective for social-ecological systems analyses. Glob. Environ. Chang. 2006, 16, 253-257. [CrossRef]

14. Aggelidis, M. Spatial Planning and Sustainable Development, 1st ed.; Simmetria: Athens, Greece, 2000; ISBN 978-960-266-113-0. (In Greek)

15. Theodora, G.; Loukakis, P. Development tendencies in the network of urban centers in Greece. Aeihoros 2011, 15, 102-129.

16. Petrakos, G.; Pavleas, S.; Anagnostou, A. The Greek Urban System: Concentration or Deconcentration, and estimation of metropolitan concentration. In The City and the Region; Eckardt, F., Hassenpflug, D., Eds.; Peter Lang: Frankfurt, Germany, 2005; pp. 117-142.

17. Beriatos, E. (Ed.) Mountainous Area: Environment-Society-Development, 1st ed.; Publications of the Foundation Kefalonia Ithaca, University of Thessaly-Department of Planning and Regional Development: Volos, Greece, 2005; ISBN 960-802-937-6. (In Greek)

18. Coccosis, H.; Psycharis, Y. (Eds.) Regional Analysis and Policy: The Greek Experience, 1st ed.; Physica-Verlag Heidelberg: Heidelberg, Germany, 2008; ISBN 978-3-7908-2570-1.

19. Papagiannis, T.; Sorotou, A. (Eds.) In Search of the Greek Landscape, 1st ed.; Mediterranean Institute for Nature and Humans (Med-INA): Athens, Greece, 2010; ISBN 978-960-89972-1-9. (In Greek)

20. Tsilimigas, G.; Gourgiotis, A. Landscape management in the context of spatial planning. Aeihoros 2014, 19, 24-37.

21. Ministry of Environment, Energy and Climate Change (Consultants: Yiannakou, A.; Moutsiakis, E.). Study of Evaluation, Review and Specialization of the Regional Framework for Spatial Planning and Sustainable Development of Western Macedonia; Ministry of Environment, Energy and Climate Change: Athens, Greece, 2013.

22. Ministry of Environment, Energy and Climate Change (Consultants: Yiannakou, A.; Moutsiakis, E.). Study of Evaluation, Review and Specialization of the Regional Framework for Spatial Planning and Sustainable Development of Western Macedonia: Landscape Study; Ministry of Environment, Energy and Climate Change: Athens, Greece, 2013.

23. Hellenic Statistical Authority. Census; Hellenic Statistical Authority: Athens, Greece, 2011.

24. Dagalides, A. Sectoral Study 17: Fur Industry. 2012. Available online: https://www.google.gr/url?sa=t\& $\mathrm{rct}=\mathrm{j} \& \mathrm{q}=\&$ \&esrc=s\&source=web\&cd=1\&ved=0ahUKEwjwmubTqq_VAhURU1AKHQkDD8YQFgglMAA\& url=http $\% 3 \mathrm{~A} \% 2 \mathrm{~F} \% 2 \mathrm{Fwww}$.piraeusbankgroup.com\%2F \%2Fmedia\%2FCom\%2FDownloads\%2FGreekSectoral-Studies\%2F2012\%2FFurs.ashx\&usg=AFQjCNEj3VKB7UlomnyEwW582PehNz1_nA (accessed on 1 June 2017).

25. Egnatia Odos Observatory. Monitoring of the Motorway's Spatial Impacts: 3rd Report of Spatial Impacts. 2015. Available online: http://observatory.egnatia.gr/reports/2015/EO_observe_3rd_impacts_report_ 2015nov.pdf (accessed on 1 June 2017).

26. Wascher, D.M. (Ed.) EU Accompanying Measure Project, European Landscape Character Assessment Initiative (ELCAI), 5th Framework Programme on Energy, Environment and Sustainable Development. In European Landscape Character Areas: Typologies, Cartography and Indicators for the Assessment of Sustainable Landscapes, Final Project Report, 1st ed.; Landscape Europe: Wageningen, The Netherlands, 2005.

27. Region of Western Macedonia. Western Macedonia: History and Culture; Greek Publications SA: Athens, Greece, 2008; ISBN 978-960-98380-0-9.

28. Region of Western Macedonia-ANKO. Business Plan 'Products Basket of Western Macedonia'; Region of Western Macedonia-ANKO: Kozani, Greece, 2012.

(C) 2017 by the authors. Licensee MDPI, Basel, Switzerland. This article is an open access article distributed under the terms and conditions of the Creative Commons Attribution (CC BY) license (http:// creativecommons.org/licenses/by/4.0/). 